\title{
Study of prevalence and effects of insulin resistance in patients with chronic hepatitis C genotype 4
}

\author{
A.F. Amer, ${ }^{1}$ M.M. Baddour, ${ }^{1}$ M.A. Elshazly, ${ }^{2}$ G. Fadally, ${ }^{3}$ N.F. Hanafi ${ }^{7}$ and S.L. Assar ${ }^{1}$
}

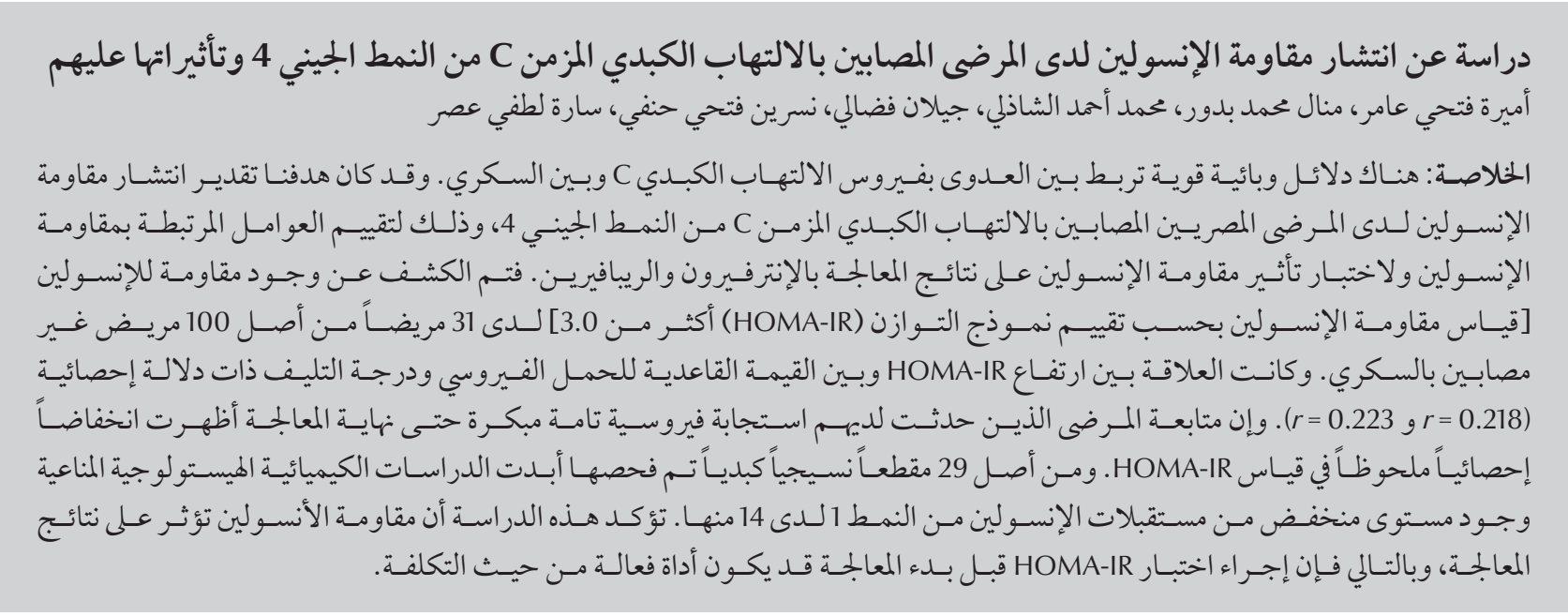

ABSTRACT There is strong epidemiological evidence linking hepatitis $\mathrm{C}$ virus (HCV) infection and diabetes. Our aim was to evaluate the prevalence of insulin resistance in Egyptian patients with chronic HCV genotype 4 infection, to assess factors associated with insulin resistance and to test the impact of insulin resistance on outcomes of treatment with pegylated interferon/ribavirin. Insulin resistance [homeostasis model assessmentinsulin resistance (HOMA-IR) score > 3.0] was detected in 31 of 100 nondiabetic patients. The relationship between elevated HOMA-IR and baseline viral load and degree of fibrosis was statistically significant $(r=0.218$ and $r=0.223$ ). Follow-up of patients with complete early virological response until the end of treatment showed a statistically significant decrease in HOMA-IR score. Out of 29 liver tissue sections examined, 14 had a low level of expression of insulin receptor type 1 by immunohistochemical studies. This study confirms that insulin resistance affects treatment outcome, and thus HOMA-IR testing before initiation of therapy may be a cost-effective tool.

Étude de la prévalence et des effets de la résistance à l'insuline chez des patients atteints d'hépatite C de génotype-4

RÉSUMÉ Il existe des données factuelles épidémiologiques fortes reliant l'infection par le virus de l'hépatite C et le diabète. Nous avions pour objectif d'évaluer la prévalence de la résistance à l'insuline chez des patients égyptiens atteints d'une infection par le virus de l'hépatite $C$ de génotype-4, d'étudier les facteurs associés à la résistance à l'insuline et de tester l'impact de la résistance à l'insuline sur les résultats du traitement par interféron pégylé/ribavirine. La résistance à l'insuline (score du modèle d'évaluation homéostatique pour l'insulinorésistance $[\mathrm{HOMA}-\mathrm{IR}]>3,0$ ) a été observée chez 31 des 100 patients non diabétiques. Le lien entre un score HOMA-IR élevé et la charge virale initiale ainsi que le degré de fibrose était statistiquement significatif $(r=0,218$ et $r=0,223$ ). Le suivi des patients ayant présenté une réponse virologique précoce et complète jusqu'à la fin du traitement a révélé une diminution statistiquement significative du score HOMA-IR. Sur les 29 coupes de tissu hépatique examinées, 14 présentaient un faible niveau d'expression du récepteur insulinique de type 1 selon les études immunohistochimiques. La présente étude confirme que la résistance insulinique influe sur les résultats du traitement. Par conséquent, le score HOMA-IR avant l'instauration d'un traitement peut être un outil d'un bon rapport coût-efficacité. 


\section{Introduction}

For many years, Egypt has been widely regarded as having an epidemic of hepatitis $\mathrm{C}$ virus (HCV) infection, with the highest recorded prevalence in the world. HCV is currently the most significant health problem in Egypt. The latest published Egyptian Demographic Health Survey in 2009 of a national probability sample of the resident population estimated an overall anti-HCV antibody prevalence of $14.7 \%$. The proportion of Egyptians estimated to be chronically infected was $9.8 \%$ (1).

The current standard treatment for chronic $\mathrm{HCV}$ infection (CHC) is pegylated interferon-alpha (peg IFN- $\alpha$ ) combined with ribavirin. Despite significant improvement in treatment efficacy during the past decade, only $50 \%$ of patients can be cured of $\mathrm{HCV}$, depending on its genotype (2). Besides being unsatisfactory, treatment of $\mathrm{HCV}$ is costly, beyond the reach of most patients in Egypt, requires 48 or more weeks to complete and has serious side-effects. New modalities of therapy using directly-acting antiviral drugs, are available in some national treatment units but are not yet fully implemented in all of them.

The spectrum of severity of liver disease associated with $\mathrm{HCV}$ varies widely and depends on both viral and host factors. Age, male sex, alcohol consumption, immune status and co-infections are defined as risk factors for a progressive course of $\mathrm{CHC}$ (3). One of the co-factors is type 2 diabetes (4). There is strong epidemiological evidence linking HCV and diabetes. Patients with $\mathrm{CHC}$ are more likely to develop type 2 diabetes (5) and diabetic patients are more likely to be infected with HCV (6). Type 2 diabetes has been recognized to worsen the course of hepatitis C. Both are now recognized as being a deadly combination (7). In view of this association, instead of looking only at the occurrence of overt type 2 diabetes, we should also consider prediabetic conditions such as insulin resistance in patients with $\mathrm{HCV}$ infection. Insulin resistance is defined as a condition in which higher than normal insulin levels are needed to achieve normal glucose metabolism or alternatively normal insulin levels fail to achieve normal glucose metabolism (8).

During recent years, basic research, clinical trials and epidemiological studies have provided evidence that HCV can independently contribute to insulin resistance (9-11). Adding to this growing body of evidence, it is now suggested that $\mathrm{HCV}$ interferes with the insulin signalling pathway using genotype-specific mechanisms (12). Insulin carries out its biological effects through phosphorylation of insulin substrate receptors 1 (IRS-1) and 2 (IRS-2) (13). Thus research has focused on IRS- 1 and -2 as the loci for insulin resistance. An association between HCV and insulin resistance would have significant clinical consequences. Mounting evidence indicates that $\mathrm{HCV}$-associated insulin resistance may cause accelerated fibrogenesis, reduced response to interferon-based therapy and hepatocellular carcinoma (14). These lifethreatening complications are different from the well-known complications of lifestyle-associated insulin resistance, namely cardiovascular diseases, renal failure and infections (15).

Increased levels of insulin resistance are associated with reduced rates of initial virological response as well as sustained virological response in $\mathrm{CHC}$ patients treated with a combination of peg IFN- $\alpha$ and ribavirin $(16,17)$. This negative association has been reported not only in patients infected with genotype 1 (17), but also in those with the so called "easy to treat" genotypes 2 and 3 (18). Conversely, development of insulin resistance or exacerbation of previously stable glycaemic control have been reported as drug side-effects in $\mathrm{CHC}$ patients who are receiving interferon treatment (19). To our knowledge, studies concerning genotype 4 , the most prevalent genotype in Egypt (20), are limited. Information regarding glucose abnormalities in $\mathrm{CHC}$ patients with genotype 4 is valuable for determining if strategies to modify insulin resistance before or during combination therapy are a feasible approach for enhancing the likelihood of treatment response.

Our aim was to evaluate the prevalence of insulin resistance in Egyptian patients chronically infected with $\mathrm{HCV}$ genotype 4, to assess factors associated with insulin resistance in those patients (viral, metabolic and histopathological, including steatosis, fibrosis and necroinflammatory changes) and to test the impact of insulin resistance on treatment outcomes in patients receiving peg IFN- $\alpha$ and ribavirin treatment.

\section{Methods}

This study was conducted from January 2013 to January 2014. The study received ethical approval from the local research committee of Alexandria Main University Hospital. All patients and controls were asked to give their informed consent before being included in the study.

\section{Study sample}

A total of 100 adult patients with $\mathrm{CHC}$ genotype 4 infection were enrolled randomly from the centre for treatment of hepatitis viruses in Sharq El Madina Hospital of Alexandria, Egypt. The hospital is one of 23 centres established by the Egyptian Ministry of Health for treating $\mathrm{CHC}$ patients as a part of the national viral hepatitis treatment programme.

All patients were eligible for treatment and non-diabetic (diabetes was diagnosed using the 1997 American Diabetes Association criterion: fasting glucose $>126 \mathrm{mg} / \mathrm{dL}$ ). The following patients were excluded from the study by appropriate virological, serological, biochemical and ultrasound data and 
by clinical history: those with clinical evidence of hepatic decompensation or liver cirrhosis, concomitant hepatitis B infection (defined as HBsAg-positive), patients with $\mathrm{CHC}$ of a genotype other than 4, autoimmune hepatitis, hemochromatosis, primary biliary cirrhosis, Wilson disease, drug-induced liver disease and laboratory values of serum creatinine $>1.5 \mathrm{mg} / \mathrm{dL}$, absolute neutrophil count $<1000 / \mathrm{mL}$, platelet count $<50000 / \mathrm{mL}$ or haemoglobin $<11 \mathrm{~g} / \mathrm{dL}$. Randomization was done on the basis of the exclusion and inclusion criteria that were applied to all patients and was performed on the days of data collection for all patients attending the treatment centre on that day.

A control group comprising 60 healthy HCV-antibody negative individuals from the general population was included in the study for comparing their homeostasis model assessment-insulin resistance (HOMA-IR) index with that of the $\mathrm{CHC}$ patients. Our controls were individuals entering the laboratory for enzyme-linked immunosorbent assay (ELISA)-HCV antibody test and, when a negative result was obtained, an additional HOMA-IR test was performed to determine their insulin resistance and to compare it with insulin resistance among $\mathrm{CHC}$ patients.

The sample size calculation for the study was done by an experienced statistician. The sampling protocol was as follows. A total of 100 patients attending the national treatment centre for $\mathrm{HCV}$ provided by the national treatment programme were to be included for a cross-sectional study of the prevalence of insulin resistance among $\mathrm{CHC} \mathrm{pa-}$ tients. From these 100 patients, $60 \mathrm{pa}$ tients were to be followed for studying the different treatment outcomes and to follow their insulin resistance state. After 12 weeks from starting treatment, 10 patients were non-responders and their treatment was stopped according to the Ministry of Health protocol. We therefore followed another 11 patients making a total of 71 patients followed for treatment response and insulin resistance.

\section{Data collection}

\section{Clinical and demographic data}

Clinical and demographic data were collected from the patients' files, including: age, sex, height, weight, waist circumference and blood pressure. Venous blood samples were collected from both cases and controls after they had fasted overnight for 12 hours, to test their lipid profile and to determine serum levels of glucose and insulin.

Body mass index (BMI) was calculated. The metabolic syndrome was diagnosed according to the revised World Health Organization (WHO) definition as the presence of 3 or more of the following criteria: central obesity (waist circumference $>102 \mathrm{~cm}$ in males or $>88 \mathrm{~cm}$ in females), hypertension (blood pressure $>135 / 85 \mathrm{mmHg}$ ), fasting plasma glucose $>110 \mathrm{mg} / \mathrm{dL}$, triglycerides $>150 \mathrm{mg} / \mathrm{dL}$, high density lipoprotein (HDL) cholesterol $<40 \mathrm{mg} / \mathrm{dL}$ (males) or $<50 \mathrm{mg} / \mathrm{dL}$ (females) (21).

\section{HOMA method}

Insulin resistance was assessed using the HOMA method using an immunoassay analyser (COBAS E insulin kit immunoassay analyser, Roche Diagnostic) and the following equation: HOMA-IR = fasting insulin $(\mu \mathrm{U} / \mathrm{mL})$ $x$ fasting glucose $(\mathrm{mmol} / \mathrm{L}) / 22.5(22)$. A HOMA-IR score $>3.0$ was considered the criterion for insulin resistance (23).

\section{Virological assessments}

Assessment of the HCV viral load of the 100 patients included in our study was done by quantitative measurement of RNA using real-time PCR (COBAS AmpliprepT/COBAS TaqManT, Roche Molecular Systems). Level of viraemia was classified as high, intermediate and low according to viral load being $>10^{6}, 10^{5}-10^{6}$ or $<10^{5} \mathrm{IU} /$ $\mathrm{mL}$ respectively (24). Determination of the genotype of the virus was done using a real-time PCR kit (AmpliSens HCV-FRT, InterLabService Ltd). The definition of the on-treatment response was as follows: complete early virological response was defined as HCV-RNA below the limit of detection at week 12. Partial early virological response was defined as positive HCV-RNA at week 12 but with $a \geq 2 \log 10$ drop in viral load as compared with baseline. End-of-treatment response was defined as serum HCV-RNA below the limit of detection at the end of treatment. We considered non-responders to be: patients with no or minimal change in their HCV-RNA titres $(<2 \log 10$ drop at week 12 as compared with baseline); those with viral load drop $>2 \log 10$ at week 12 as compared with baseline and who still had positive HCV-RNA at week 24; those who became HCVRNA positive after negativization before the end of treatment (breakthrough response); and those who became HCV-RNA positive after negativization at the end of treatment (25).

\section{Treatment outcomes}

From the 100 patients enrolled in the study, 71 treatment-naive $\mathrm{CHC}$ patients (i.e. those who had not had received any form of treatment for HCV by any private- or government-sector physician) were followed for treatment outcomes associated with various degrees of insulin resistance. All patients were started on treatment with a combination of peg INF- $\alpha$ and ribavirin for an intended duration of 48 weeks, as in the protocol of the national HCV programme.

Serum HCV-RNA levels were assessed in all patients at baseline and then at weeks 12, 24 and 48. After 12 weeks, the early virological response was assessed by measuring the viral load and the HOMA-IR score was determined. Patients who did not demonstrate a decrease in viral load of 2 log or more were considered early non-responders $(n=$ 10) (26). Therapy was discontinued for these patients according to the protocol 
approved by the Ministry of Health. Patients showing a $\geq 2 \log$ reduction in viral load continued the antiviral treatment regimen until 48 weeks $(n=61)$. Viral load and insulin resistance were reassessed again after 48 weeks of therapy.

\section{Liver histopathology and immuno-} histochemistry

All patients underwent an ultrasoundguided percutaneous liver biopsy prior to the start of treatment and patients with hemochromatosis or primary biliary cirrhosis were excluded. The degree of necroinflammatory activity and of fibrosis were scored based on the Metavir system (27). Hepatic steatosis was scored as the percentage of hepatocytes containing macrovesicular fat droplets and was graded from 0 to 3 (28). Paraffin-embedded liver sections from selected patients were deparaffinized and subjected to immunohistochemical staining using an anti-human-IRS-1 (Ultravision detection system antipolyvalent, HRP/ DAB kit, Thermo Fischer Scientific) to examine the protein expression levels of IRS-1 (29).

\section{Statistical analysis}

The data were analysed using SPSS software package, version 20.0. Qualitative data were described using numbers and percentages. Quantitative data were described using the range (minimum and maximum), mean, standard deviation (SD) and median. Comparison between cases and controls was performed using the chi-squared test. The distributions of quantitative variables were tested for normality using Kolmogorov-Smirnov, Shapiro-Wilk and D'Agostino tests. If they revealed normal data distributions, parametric tests were applied. If the data were abnormally distributed, non-parametric tests were used. For abnormally distributed data, comparison between cases and controls was done using the MannWhitney test, while the Kruskal-Wallis test was used to compare between
HOMA-IR categories. Correlations between HOMA-IR with different parameters were assessed using Spearman coefficient. Significance test results were quoted as 2-tailed probabilities. Significance of the obtained results was judged at the $5 \%$ level.

\section{Results}

Among the $100 \mathrm{CHC}$ patients included in the study, 40 were males and 60 were females, with a mean age of 42.8 (SD 10.2) years. The mean BMI was 27.1 (SD 3.4$) \mathrm{kg} / \mathrm{m}^{2}$. A total of 15 patients fulfilled the criteria for the metabolic syndrome. According to the Metavir score, necroinflammation was moderate to severe in $45.0 \%$ of patients and fibrosis was significant in $49.0 \%$ of cases. Steatosis was moderate in $20.7 \%$ of cases and severe in $10.3 \%$ of cases.

\section{Distribution of studied cases according to baseline viral load}

The distribution of the 100 patients included in this study with respect to their baseline viral load was as follows: $22.0 \%$ had low level viraemia, $43.0 \%$ had intermediate level viraemia and 35.0\% had high level viraemia. The median viral load was $487.3 \times 10^{3} \mathrm{IU} / \mathrm{mL}$ with mean value of $2400.9($ SD 6854.8$) \times 10^{3}$ $\mathrm{IU} / \mathrm{mL}$.

\section{Results of HOMA-IR}

Insulin resistance was detected in 31 of the 100 non-diabetic CHC patients infected with genotype 4 (HOMA-IR > 3.0). When HOMA-IR scores were categorized into 3 groups $(<2,2-4$ and $>4$ ), a highly significant difference was seen between patients and controls; for example, $49.0 \%$ of patients versus $73.3 \%$ of controls had HOM-IR $<2(P=0.001)$ (Figure 1). The mean HOMA-IR scores of cases and controls were significantly different: 2.55 (SD 2.36) versus $1.61($ SD 1.29) $(P<0.001)$ (Table 1).

\section{Relationship between HOMA- IR and clinical and biological variables}

Data on the relationship between HOMA-IR and clinical and biological variables are shown in Table 2. HOMAIR tended to correlate positively with age, baseline viral load, BMI, serum triglycerides, fibrosis and steatosis and negatively with total cholesterol, low- and high-density lipoprotein cholesterol and total lipids. Statistically significant correlations were found between elevated HOMA-IR and both baseline viral load (Spearman $r=0.218$, $P=0.029)$ and degree of fibrosis $(r=$ $0.223, P=0.026$ ).

When the data were analysed by multivariate linear regression, the results showed that viral load remained the only independent factor associated with elevated HOMA-IR levels $(P=0.001)$.

\section{Relationship between insulin resistance and treatment response}

Patients with a lower baseline HOMA score had more favourable outcomes regarding response to therapy. Patients who reached complete early virological response had statistically significant lower HOMA scores than non-responders (Table 3). All patients with complete and partial early virological response achieved end-of-treatment response with no breakthrough response.

The values of HOMA-IR test at the start of therapy, after 12 weeks and after 48 weeks of therapy in $\mathrm{CHC}$ patients who attained complete early virological response showed a considerable decline in HOMA-IR level $(P<0.001)$, suggesting that insulin resistance improved with successful treatment (Table 4).

\section{Relation between immunohistochemistry and HOMA-IR before therapy}

The expression of IRS-1 was estimated by immunohistochemical staining of 29 liver tissue sections of $\mathrm{CHC}$ cases included in the study. The results were 


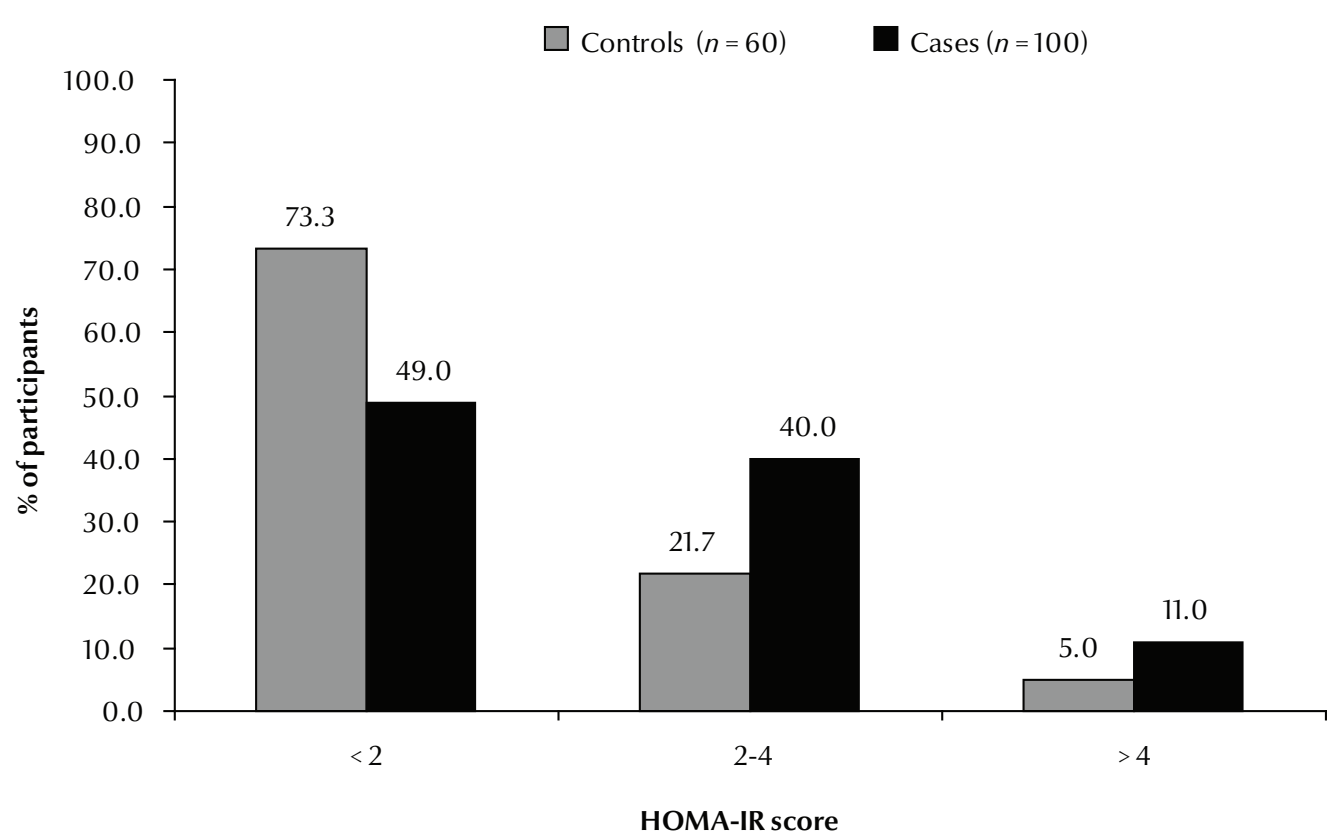

Figure 1 Comparison of homeostatic model assessment-insulin resistance (HOMA-IR) scores in patients with chronic hepatitis $C$ genotype 4 and control subjects at the 3 different cut-off levels $(<2,2-4,>4)\left(\chi^{2}=9.168 ; P=0.009\right)$

as follows: 9 cases were grade 0 (10\% positive cells), 6 cases were $1+(10-50 \%$ positive cells with weak staining), 10 cases were $2+(10-50 \%$ positive cells with strong staining or $50 \%$ positive cells with weak staining) and 4 were cases $3+(50 \%$ positive cells with strong staining) (Figure 2) (30). No statistically significant difference was found between any grades of immunohistochemistry and HOMA-IR score before therapy $(P=0.942)$.

\section{Discussion}

This study was conducted to determine the prevalence of insulin resistance in non-diabetic patients with $\mathrm{CHC}$ genotype 4 and its effect on therapy and to reveal whether application of a simple and relatively inexpensive test for assessment of insulin resistance (HOMA score) before starting antiviral therapy will lead to better selection of patients who are candidates for successful treatment. The mean HOMA-IR score of the 100 patients undergoing treatment with dual therapy (peg-INF- $\alpha$ plus ribavirin) was 2.55 (SD 2.36). Insulin resistance, defined as HOMA-IR score > 3.0, was detected in 31 patients. In a study by Khattab et al., also conducted on CHC patients with genotype 4, the mean pretreatment HOMA-IR scores (using the cut-off > 2) was 2.82 (SD 1.19) (25). Similarly, Ezzat et al. found that among CHC genotype 4 patients 31 (40.7\%) had insulin resistance, defined as HOMA-IR score $>2$, and the mean HOMA-IR was 2.6 (31). Moucari et al. also studied $\mathrm{CHC}$ genotype 4 patients and found the HOMA-IR (using the cut-off > 3) was 3.7 (SD 4.0) (23). In Asselah et al.'s study of CHC genotype 4 patients the proportion with HOMAIR > 3 was $32.4 \%$ (32).

In the correlational analysis, baseline viral load was a statistically significant factor affecting pre-treatment HOMAIR $(P=0.029)$ and was the major independent factor associated with high HOMA-IR by linear regression analysis $(P=0.001)$. Similarly, Asselah et al. found that insulin resistance was significantly associated with basal viral load in univariate analysis $(P=0.008)$ as well as multiple logistic regression analysis $(P=0.02)(32)$. Moucari et al. also showed that insulin resistance had a statistically significant correlation with

\begin{tabular}{|c|c|c|c|c|c|}
\hline \multirow[t]{2}{*}{ Group } & \multicolumn{3}{|c|}{ HOMA-IR score } & \multicolumn{2}{|c|}{ Mann-Whitney test } \\
\hline & Mean (SD) & Median & Min.-Max. & Z-value & $P$-value \\
\hline Controls $(n=60)$ & $1.61(1.29)$ & 1.41 & $0.03-6.81$ & 3.322 & 0.001 \\
\hline Cases $(n=100)$ & $2.55(2.36)$ & 2.05 & $0.23-15.17$ & & \\
\hline
\end{tabular}

$S D=$ standard deviation. 


\begin{tabular}{lcc}
\hline \multicolumn{3}{l}{$\begin{array}{l}\text { Table } 2 \text { Univariate analysis of correlations } \\
\text { assessment-insulin resistance (HOMA-IR) }\end{array}$} \\
with chronic hepatitis C genotype 4 & score and different variables in patients \\
\hline Variable & $\boldsymbol{r}_{\mathrm{s}}$ & \\
& 0.101 & $\boldsymbol{P}$-value \\
Age & 0.218 & 0.315 \\
Viral load & 0.151 & 0.029 \\
BMI & -0.098 & 0.133 \\
Total cholesterol & 0.118 & 0.338 \\
Triglycerides & -0.081 & 0.246 \\
HDL cholesterol & -0.120 & 0.430 \\
LDL cholesterol & -0.037 & 0.238 \\
Total lipids & 0.223 & 0.716 \\
Fibrosis grade & 0.336 & 0.026 \\
Steatosis grade &
\end{tabular}

$r_{s}=$ Spearman correlation coefficient .

$B M I=$ body mass index $; H D L=$ high-density lipoprotein $\angle D L=$ low-density lipoprotein .

serum HCV-RNA in univariate analysis $(P<0.001)$ and also in multiple logistic regression analysis $(P=0.002)(23)$. Our finding supports the hypothesis that HCV has a direct effect on insulin resistance progression in $\mathrm{CHC}$ patients. In contrast, another study by Ezzat et al. showed that insulin resistance had no impact on early virological response with combined therapy, on viral load or on necroinflammation (31). The contradiction between the findings of the current study and those of Ezzat et al. may be because they assessed HOMA-IR before therapy and at 12 weeks after therapy only and did not measure HOMA-IR at the end of treatment.

Concerning the relationship between pre-treatment values of
HOMA-IR and response to therapy in patients with genotype $4 \mathrm{CHC}$ infection, we concluded that having a lower baseline HOMA score led to a favourable therapeutic outcome. There was a statistically significant difference comparing the HOMA-IR of patients achieving complete early virological response, partial early virological response and non-response $(P=0.006)$. Likewise, Khattab et al. found a highly and significant relationship between insulin resistance and treatment response $(P$ $<0.001$ ) (25). Similarly, Moucari et al. concluded from their study that $\mathrm{HO}$ MA-IR score $<2$ was associated with early virological response $(P<0.001)$ and also remained an independent predictor of sustained virological response by multiple logistic regression analysis $(P=0.03)(23)$.

This research also studied the effect of successful treatment on the insulin resistance state in the selected $\mathrm{CHC}$ patients. Follow-up of the complete early virological responders until the end of treatment showed that they had a statistically significant decrease

\begin{tabular}{|c|c|c|c|c|c|}
\hline \multirow[t]{2}{*}{ Response to therapy } & \multicolumn{3}{|c|}{ HOMA-IR scores } & \multicolumn{2}{|c|}{ Mann-Whitney test } \\
\hline & Mean (SD) & Median & Min.-Max. & $\boldsymbol{P}_{l}$ & $\boldsymbol{P}_{2}$ \\
\hline Early non-responders $(\boldsymbol{n}=10)$ & $2.95(1.14)$ & 3.07 & $1.10-4.67$ & - & $\mathrm{n} / \mathrm{a}$ \\
\hline Partial early virological response $(\boldsymbol{n}=7)$ & $3.98(2.13)$ & 3.66 & $1.90-8.24$ & $0.435^{\mathrm{a}}$ & - \\
\hline Complete early virological response $(\boldsymbol{n}=54)$ & $2.32(2.35)$ & 1.64 & $0.37-11.66$ & $0.037^{\mathrm{a}}$ & $0.007^{b}$ \\
\hline Kruskal-Wallis test & \multicolumn{3}{|c|}{$\chi^{2}=10.303^{c} ; P=0.006$} & & \\
\hline
\end{tabular}

${ }^{a}$ Versus early non-responders; ${ }^{b}$ Versus partial early virological response; ${ }^{c}$ Comparing groups.

$S D=$ standard deviation

\begin{tabular}{|c|c|c|c|c|c|}
\hline \multirow[t]{2}{*}{ Follow-up interval } & \multicolumn{3}{|c|}{ HOMA-IR scores } & \multicolumn{2}{|c|}{ Wilcoxon signed ranks test } \\
\hline & Mean (SD) & Median & Min.-Max. & $P_{1}$ & $P_{2}$ \\
\hline Pre-treatment $(n=54)$ & $2.32(2.35)$ & 1.64 & $0.37-11.7$ & - & $\mathrm{n} / \mathrm{a}$ \\
\hline After 12 weeks therapy $(n=54)$ & $2.20(2.63)$ & 1.39 & $0.20-15.1$ & $0.081^{\mathrm{a}}$ & - \\
\hline After 48 weeks therapy $(n=52)$ & $1.66(1.61)$ & 1.20 & $0.13-10.5$ & $<0.001^{\mathrm{a}}$ & $<0.001^{\mathrm{b}}$ \\
\hline Friedman test & \multicolumn{3}{|c|}{$\chi^{2}=27.038^{c} ; P<0.001$} & & \\
\hline
\end{tabular}

${ }^{a}$ Versus pre-treatment; ${ }^{b}$ Versus 12 weeks follow-up; ${ }^{c}$ Comparing groups.

$S D=$ standard deviation. 


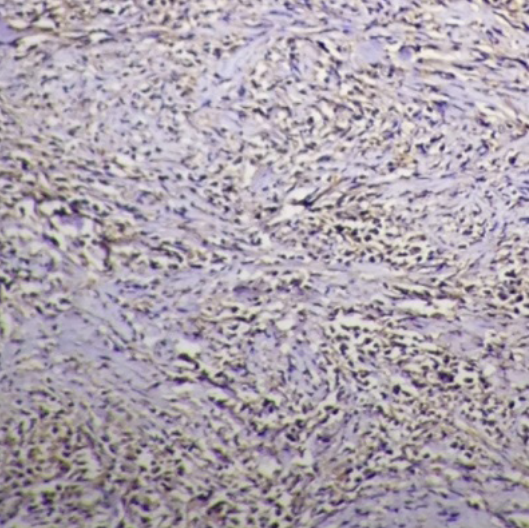

a

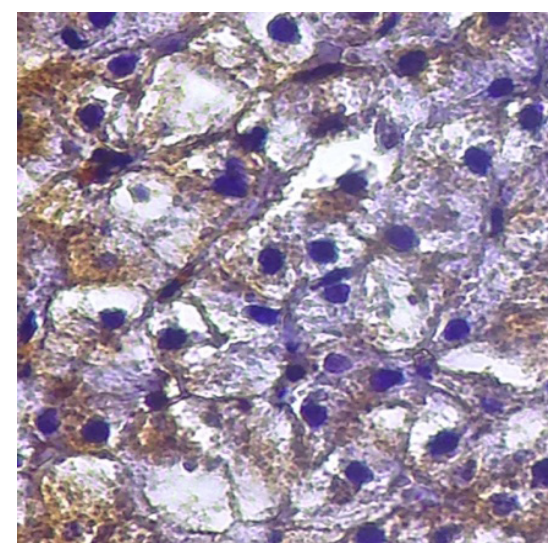

b

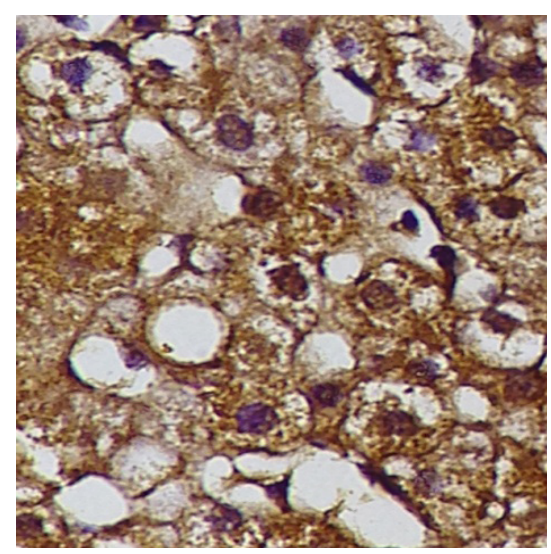

Figure 2 Immunostaining findings of (a) breast cancer tissue sections used as controls; (b) grade 3+ of liver sections of selected patients with chronic hepatitis C genotype 4; (c) grade 1+ of liver sections of selected patients

in HOMA-IR $(P<0.001)$. Similarly, Brandman et al. showed that patients had a substantial decrease in insulin resistance level 6 months after receiving antiviral therapy in comparison with those not receiving treatment (33).

In this study, 29 liver tissue sections from selected cases were tested by immunohistochemistry for expression of IRS- 1 to assess viral role in induction of insulin resistance state. Fourteen cases showed a high level of IRS- 1 expression (grades 2+ and 3+) and 15 cases had a low level of expression (grades 0 and $1+$ ) and there was no significant difference. Kawaguchi et al. demonstrated a 2 - and 3-fold increase in the intensities of IRS- 1 and IRS- 2 staining respectively after antiviral therapy. They identified mechanisms for HCV-associated insulin resistance, postulating that $\mathrm{HCV}$ core downregulates hepatic expression of IRS- $1 / 2$, and thus decreases the downstream signalling effect of insulin on glucose uptake by cells (34). Almost half of the cases in our study showed a low level of expression of IRS-1, a finding that also supports the hypothesis of a direct role of the virus on cells.

The limitations in this study may be that a specified cut-off value for HOMAIR to diagnose insulin resistance in patients was not found. Other studies have used a range of different cut-offs of HOMA-IR for diagnosis of insulin resistance (2-4). In this study we used the highest possible value to avoid misdiagnosis but this may have given a false low prevalence of insulin resistance among $\mathrm{CHC} \mathrm{pa-}$ tients. Another limitation was the limited number of tissue sections available for immunohistochemical studies and this may also have affected the analysis of the direct role of the virus in inducing insulin resistance. Also, work-up for studying the effect of the interleukin-28B (IL28B) gene on insulin resistance in our patients was not done, nor was follow-up done for studying sustained virological response in these patients.

The possibility that $\mathrm{HCV}$ is a cause of insulin resistance in chronically infected patients has important implications. From the management point of view, we can ask: Should patients with $\mathrm{CHC}$ be monitored regularly for insulin resistance? HOMA-IR is a practical and well-accepted method of measuring insulin resistance and is a non-invasive, inexpensive test that can be implemented easily in routine clinical practice. Our study provides further evidence that insulin resistance affects treatment outcome and that HOMA-IR testing before initiation of therapy may be a cost-effective tool to be considered before treating patients. Moreover, this study supports the use of strategies to modify insulin resistance before or during combination therapy as a feasible approach for enhancing the likelihood of treatment response, especially for $\mathrm{HCV}$ genotype 4 patients. This study also points to future research on the effect of glucose abnormalities on newly approved drug therapies with directly acting antivirals, as they may be an attractive alternative for treating insulin-resistant $\mathrm{CHC}$ patients.

Finding: None declared.

Competing interests: None declared.

\section{References}

1. Mohamoud YA, Mumtaz GR, Riome S, Miller D, Abu-Raddad LJ. The epidemiology of hepatitis C virus in Egypt: a systematic review and data synthesis. BMC Infect Dis. 2013;13:288.

2. Kamal SM, Nasser IA. Hepatitis C genotype 4: What we know and what we don't yet know. Hepatology. 2008 Apr;47(4):1371-83. PMID:18240152
3. Thomas DL, Seeff LB. Natural history of hepatitis C. Clin Liver Dis. 2005 Aug;9(3):383-98, vi. PMID:16023972

4. Kita Y, Mizukoshi E, Takamura T, Sakurai M, Takata Y, Arai K, et al. Impact of diabetes mellitus on prognosis of patients infected with hepatitis C virus. Metabolism. 2007 Dec;56(12):16828. PMID:17998021 
5. Huang JF, Dai CY, Hwang SJ, Ho CK, Hsiao PJ, Hsieh MY, et al. Hepatitis $\mathrm{C}$ viremia increases the association with type 2 diabetes mellitus in a hepatitis B and C endemic area: an epidemiological link with virological implication. Am J Gastroenterol. 2007 Jun;102(6):1237-43. PMID:17531012

6. Chen HF, Li CY, Chen P, See TT, Lee HY. Seroprevalence of hepatitis B and C in type 2 diabetic patients. J Chin Med Assoc. 2006 Apr;69(4):146-52. PMID:16689194

7. Hepatitis $\mathrm{C}$ and diabetes: A deadly combination [Internet] London: The Hepatitis C Trust; 2010 (http://hepctrust-archive. nam.org.uk//, accessed 25 August 2015).

8. Bugianesi E, McCullough AJ, Marchesini G. Insulin resistance: a metabolic pathway to chronic liver disease. Hepatology. 2005 Nov;42(5):987-1000. PMID:16250043

9. Hui JM, Sud A, Farrell GC, Bandara P, Byth K, Kench JG, et al Insulin resistance is associated with chronic hepatitis $C$ virus infection and fibrosis progression [corrected]. Gastroenterology. 2003 Dec;125(6):1695-704. PMID:14724822

10. Hsu CS, Liu CJ, Liu CH, Wang CC, Chen CL, Lai MY, et al. High hepatitis $\mathrm{C}$ viral load is associated with insulin resistance in patients with chronic hepatitis C. Liver Int. 2008 Feb;28(2):271-7. PMID:18028320

11. Yoneda M, Saito S, Ikeda T, Fujita K, Mawatari H, Kirikoshi H, et al. Hepatitis $C$ virus directly associates with insulin resistance independent of the visceral fat area in nonobese and nondiabetic patients. J Viral Hepat. 2007 Sep;14(9):600-7. PMID:17697011

12. Neuschwander-Tetri BA. Hepatitis C virus-induced insulin resistance: not all genotypes are the same. Gastroenterology. 2008 Feb;134(2):619-22. PMID:18242225

13. Mangia A, Ripoli M. Insulin resistance, steatosis and hepatitis $C$ virus. Hepatol Int. 2013 Dec;7 Suppl 2:782-9. PMID:24587848

14. Huang JF, Yu ML, Dai CY, Chuang WL. Glucose abnormalities in hepatitis C virus infection. Kaohsiung J Med Sci. 2013 Feb;29(2):61-8. PMID:23347806

15. Jansson SP, Andersson DK, Svärdsudd K. Mortality trends in subjects with and without diabetes during 33 years of followup. Diabetes Care. 2010 Mar;33(3):551-6. PMID:20009100

16. Bortoletto G, Realdon S, Dal Pero F, Gerotto M, Scribaro L, Boninsegna $S$, et al. Insulin resistance (IR) defined by the homeostosis model of assessment insulin resistance (HOMA-IR) index has a direct effect on early viral kinetics during pegylated-interferon therapy for chronic hepatitis C. Hepatology. 2007; $46: 361$

17. Chu CJ, Lee SD, Hung TH, Lin HC, Hwang SJ, Lee FY, et al. Insulin resistance is a major determinant of sustained virological response in genotype 1 chronic hepatitis $C$ patients receiving peginterferon alpha-2b plus ribavirin. Aliment Pharmacol Ther. 2009 Jan;29(1):46-54. PMID:18680550

18. Poustchi H, Negro F, Hui J, Cua IH, Brandt LR, Kench JG, et al. Insulin resistance and response to therapy in patients infected with chronic hepatitis $\mathrm{C}$ virus genotypes 2 and 3. J Hepatol. 2008 Jan;48(1):28-34. PMID:17977612

19. Imano E, Kanda T, Ishigami $Y$, Kubota M, Ikeda M, Matsuhisa $\mathrm{M}$, et al. Interferon induces insulin resistance in patients with chronic active hepatitis C. J Hepatol. 1998 Feb;28(2):189-93. PMID:9514530

20. Ray SC, Arthur RR, Carella A, Bukh J, Thomas DL. Genetic epidemiology of hepatitis $C$ virus throughout egypt. J Infect Dis. 2000 Sep;182(3):698-707. PMID:10950762

21. Alberti KG, Zimmet P, Shaw J; IDF Epidemiology Task Force Consensus Group. The metabolic syndrome-a new world- wide definition. Lancet. 2005 Sep 24-30;366(9491):1059-62. PMID:16182882

22. Kawaguchi T, Yoshida T, Harada M, Hisamoto T, Nagao Y, Ide $T$, et al. Hepatitis $C$ virus down-regulates insulin receptor substrates 1 and 2 through up-regulation of suppressor of cytokine signaling 3. Am J Pathol. 2004 Nov;165(5):1499-508. PMID:15509521

23. Moucari R, Ripault M-P, Martinot-Peignoux M, Voitot $H$, Cardoso A-C, Stern C, et al. Insulin resistance and geographical origin: major predictors of liver fibrosis and response to peginterferon and ribavirin in HCV-4. Gut. 2009 Dec;58(12):1662-9. PMID:19671541

24. Farag RE, Arafa MM, El-Etreby S, Saudy NS, Eldeek BS, ElAlfy HA, et al. Human leukocyte antigen class I alleles can predict response to pegylated interferon/ribavirin therapy in chronic hepatitis C Egyptian patients. Arch Iran Med. 2013 Feb;16(2):68-73.

25. Khattab M, Eslam M, Sharwae MA, Shatat M, Ali A, Hamdy L.Insulin resistance predicts rapid virologic response to peginterferon/ribavirin combination therapy in hepatitis C genotype 4 patients. Am J Gastroenterol. 2010 Sep;105(9):1970-7. 2PMID:20234345

26. Lee SS, Abdo AA. Predicting antiviral treatment response in chronic hepatitis C: how accurate and how soon? J Antimicrob Chemother. 2003 Mar;51(3):487-91. PMID:12615848

27. Rammeh S, Khadra HB, Znaidi NS, Romdhane NA, Najjar T, Bouzaidi S, et al. [Inter-observes agreement of Ishak and Metavir scores in histological evaluation of chronic viral hepatitis B and Cl. Ann Biol Clin (Paris). 2014 Jan-Feb;72(1):57-60. PMID:24492098

28. Cholet F, Nousbaum JB, Richecoeur M, Oger E, Cauvin JM, Lagarde $\mathrm{N}$, et al. Factors associated with liver steatosis and fibrosis in chronic hepatitis C patients. Gastroenterol Clin Biol. 2004 Mar;28(3):272-8. PMID:15094677

29. Brandman D, Bacchetti P, Ayala CE, Maher JJ, Khalili M. Impact of insulin resistance on $\mathrm{HCV}$ treatment response and impact of HCV treatment on insulin sensitivity using direct measurements of insulin action. Diabetes Care. 2012 May;35(5):1090-4. PMID:22399695

30. Koda M, Sulkowska M, Kanczuga-Koda L, Sulkowski S. Expression of insulin receptor substrate 1 in primary breast cancer and lymph node metastases. J Clin Pathol. 2005 Jun;58(6):645-9. PMID:15917419

31. Wafaa E, Yasser AE, Nour AA, Hala MR, Omneya MS, Mona HI, et al. Insulin resistance and early virological response in chronic HCV infection. J Genetic Engin and Biotech. 2013;11:69-73.

32. Moucari R, Asselah T, Cazals-Hatem D, Voitot H, Boyer N, Ripault MP, et al. Insulin resistance in chronic hepatitis $C$ : association with genotypes 1 and 4, serum HCV RNA level, and liver fibrosis. Gastroenterology. 2008 Feb;134(2):416-23. PMID:18164296

33. Brandman D, Bacchetti P, Ayala CE, Maher JJ, Khalili M. Impact of insulin resistance on $\mathrm{HCV}$ treatment response and impact of HCV treatment on insulin sensitivity using direct measurements of insulin action. Diabetes Care. 2012 May;35(5):1090-4. PMID:22399695

34. Kawaguchi $\mathrm{Y}$, Mizuta T. Interaction between hepatitis $\mathrm{C}$ virus and metabolic factors. World J Gastroenterol. 2014 Mar 21;20(11):2888-901. PMID:24659880 